\title{
Sodium tanshinone IIA sulfonate ameliorates cerebral ischemic injury through regulation of angiogenesis
}

\author{
JIAZHEN XU ${ }^{1 *}$, PEI ZHANG ${ }^{1 *}$, YAO CHEN ${ }^{1 *}$, YULAN XU $^{2}$, PENGWEI LUAN ${ }^{2}$, \\ YUYING ZHU ${ }^{1}$ and JIANGE ZHANG ${ }^{1}$
}

\begin{abstract}
${ }^{1}$ Research Center of Chiral Drugs, Innovation Research Institute of Traditional Chinese Medicine, Shanghai University of Traditional Chinese Medicine, Shanghai 201203; ${ }^{2}$ Institute of Drug Discovery and Development, School of Pharmaceutical Sciences, Zhengzhou University, Zhengzhou, Henan 450001, P.R. China
\end{abstract}

Received January 25, 2021; Accepted May 26, 2021

DOI: $10.3892 / \mathrm{etm} .2021 .10556$

\begin{abstract}
Vascular remodeling and neuroprotection are two major adaptable methods for treating ischemic stroke. Edaravone is a protective agent for the treatment of stroke and was used as a positive control in the present study. Sodium tanshinone IIA sulfonate (STS) has demonstrated therapeutic clinical effects in cerebral infarction in China, while its mechanisms of action in ischemic stroke have remained elusive. The angiogenesis and neuroprotective effects of STS were evaluated in a rat model induced by middle cerebral artery occlusion and 3 days of reperfusion. When used at the same dose, the magnitude of the therapeutic effect of STS was similar to that of edaravone in terms of decreased blood-brain barrier damage as indicated by reduced Evans blue leakage, improved neurological deficits, alleviated cerebral edema and inhibition of histopathological changes caused by ischemia/reperfusion. The TUNEL assay demonstrated that the ability of STS to inhibit neuronal apoptosis was equivalent to that of edaravone. Immunofluorescence detection of CD31 and $\alpha$-smooth muscle actin indicated that the vascular density was significantly reduced in the vehicle group compared with that in the sham operation group, STS increased the microvessel density in the ischemic area. Furthermore, in the vehicle group the protein expression of vascular endothelial growth factor (VEGF) and VEGF receptor 2 (VEGFR) as determined by fluorescence microscopy and immunohistochemistry was significantly reduced compared with that in the sham group.
\end{abstract}

Correspondence to: Professor Jiange Zhang or Dr Yuying Zhu, Research Center of Chiral Drugs, Innovation Research Institute of Traditional Chinese Medicine, Shanghai University of Traditional Chinese Medicine, 1200 Cailun Road, Shanghai 201203, P.R. China E-mail: jgzhang@shutcm.edu.cn

E-mail: ying.yu.zhu@163.com

\section{*Contributed equally}

Key words: sodium tanshinone IIA sulfonate, stroke, VEGF, angiogenesis, brain protection
However, STS promoted their expression compared to the vehicle group respectively, and increaed the mRNA expression of VEGF, VEGFR, CD31 and angiopoietin-1 as determined by reverse transcription-quantitative PCR, but these changes were not significant or not present for edaravone apart from Ang-1. In conclusion, STS protected against ischemic brain injury by promoting angiogenesis in ischemic areas and inhibiting neuronal apoptosis. These results provide a potential treatment for stroke recovery.

\section{Introduction}

Stroke ranks fifth among all causes of human death and most patients have a stroke survive with serious long-term disability $(1,2)$. Ischemic stroke caused by blocked blood supply is observed in $\sim 87 \%$ of all patients with stroke. At present, thrombolytic therapy with recombinant tissue plasminogen activator is recommended by guidelines for the treatment of grade A stroke in numerous countries. However, the effectiveness of this therapy depends on the limited time window of stroke symptoms. Currently, post stroke rehabilitation is still an effective way to treat stroke (3). Thus, restoring blood flow and recovering injured neurons are considered to be crucial methods for the treatment of stroke.

Sodium tanshinone IIA sulfonate (STS) is a water-soluble substance obtained by sulfonating the diterpenoid quinone compound tanshinone IIA, which is isolated from Salvia miltiorrhiza, a plant of the Labiatae family (4). Tanshinone IIA has poor water solubility; therefore, STS was developed to increase bioavailability and has been successfully used to treat patients with cardiovascular diseases, cerebrovascular disease and nervous system diseases such as Alzheimer's disease and cerebral ischemia (5-7). STS may improve myocardial injury mainly by inhibiting oxidative stress (8), inhibiting inflammatory actions (9) and promoting angiogenesis (10). Studies have indicated that STS protects against brain injury, promotes nerve regeneration (11) and ameliorates blood-brain barrier (BBB) damage caused by ischemia (12). STS is able to promote the integrity (13) and angiogenesis of vascular endothelial cells (14). However, it has remained elusive whether STS has an effect on promoting angiogenesis in cerebral ischemic injury. 
After stroke, nerve cells in the ischemic penumbra are impaired but they are still able to survive for a short duration, which is a reversible state $(15,16)$. The survival and functional recovery of brain tissue after ischemic stroke depends on cerebral ischemic reperfusion and the establishment of a functional collateral circulation (13). Extensive experimentation has proven that the angiogenic response has an important role in the recovery of neurological function in the delayed phases of stroke disease $(17,18)$. Angiogenesis may improve tissue microperfusion in ischemic boundary regions and reduce infarct volumes $(19,20)$. Studies have revealed that angiogenesis not only provides a sufficient supply of oxygen and nutrients for the repair of neurons, but also offers a favorable microenvironment for neuron regeneration after brain damage (21). These features are beneficial for long-term functional recovery. Therefore, enhancement of angiogenesis is one of the strategies for facilitating functional recovery from acute injury to delayed repair period (22).

Vascular endothelial growth factor (VEGF) represents one of the most important modulators in promoting postischemia neurovascular remodeling $(23,24)$. Ischemia stimulates VEGF expression in the brain (25), thereby promoting the formation of new cerebral blood vessels (26). VEGF may exert mitogenic and antiapoptotic effects on endothelial cells, which increase vascular permeability and promote cell migration (27). VEGF exerts its biological functions through two closely related tyrosine kinase receptors, VEGF receptor (VEGFR)1 and VEGFR2 (28). Previous studies have indicated that VEGF has a significant role in promoting postischemia neurovascular recovery by regulating VEGFR2 signaling (23). Angiopoietin-1 (Ang-1) is also an important factor in promoting angiogenesis. It has been suggested that Ang-1 may enhance the effects of other angiogenic cytokines and maintain the integrity of the neovascularization structure (29).

In the present study, the protective effects of STS on middle cerebral artery occlusion reperfusion injury and angiogenesis were investigated in Sprague Dawley (SD) rats and edaravone was used as a positive control. Furthermore, the mechanisms by which STS promotes angiogenesis in brain tissue was preliminarily explored.

\section{Materials and methods}

Animals. A total of 92 adult male SD rats (7-8 weeks, 280-320 g) were purchased from Sino-British SIPPR/BK Lab. Animal Co., Ltd.. The rats were individually caged in a climate-controlled room $\left(20-26^{\circ} \mathrm{C}\right.$, relative humidity of $\left.40-70 \%\right)$ and maintained on a 12-h light/dark cycle, and they were allowed free access to water and food. All of the animal experiments were approved by the Ethics Committee of the animal experiment center of Shanghai University of Traditional Chinese Medicine (no. PZSHUTCM19010411) and experiments were performed in accordance with the guidelines of the regulation for the administration of affairs concerning experimental animals of China enacted in 1988. All efforts were made to minimize the number of animals experiencing stress and pain.

The rats were randomly assigned to four groups containing 20 animals each: i) Sham group (treated with saline); ii) vehicle group [middle cerebral artery occlusion (MCAO)/reperfusion model treated with saline]; iii) STS group (MCAO/reperfusion model treated with STS); and iv) positive control group (MCAO/reperfusion model treated with edaravone). STS was purchased from Xi'an Tongze Biotechnology Co., Ltd. and edaravone was obtained from Zhejiang Shengtong Biotechnology Co., Ltd.. Different concentrations of STS and edaravone (4 animals each dose) were screened as follows: STS [5, 15 or $30 \mathrm{mg} / \mathrm{kg}$ body weight dose selection was based on previous references $(30,31)]$ and edaravone $(5$ or $30 \mathrm{mg} / \mathrm{kg}$ body weight dose selection was based on the maximum and minimum doses of STS) dissolved in saline was intraperitoneally injected $2 \mathrm{~h}$ after reperfusion and then once a day for 3 days.

MCAO and reperfusion in rats. All SD rats were anesthetized with isoflurane prior to the experiments (3\% of induction dose and $2.5 \%$ of maintenance dose). Focal ischemic infarction was induced by occlusion of the left MCA as described previously (32). In brief, an incision was performed in the midline of the rat neck to isolate the common carotid artery, external carotid artery and internal carotid artery. The common carotid artery and the external carotid artery were then ligated with a 4-0 nonabsorbent suture and a monofilament nylon suture was inserted from the common carotid artery to block the blood flow of the middle cerebral artery. Subsequently, the skin incision was closed and the anesthesia was stopped. After ischemia for $2 \mathrm{~h}$, the nylon suture on the carotid arteries was removed and the rats were returned to their cages to allow blood reperfusion for $72 \mathrm{~h}$. During the whole operation, the rats were kept in a $37^{\circ} \mathrm{C}$ environment. After the skin incision was closed, the anesthesia was stopped and the rats were returned to their cages. The mental status of rats was closely observed by the experimenter on the cage-side once a day during the experimental period, and euthanasia was performed when the rats developed soft paralysis of the limbs with no spontaneous activity. This only occurred in a few rats, and the rats without the aforementioned conditions were used for subsequent experiments and the brain tissues were harvested after anesthesia at the end of the experiment. The sham operation group of rats received the same operation except for nylon suture insertion.

Staining of infarcted brain tissues. On the third day after the operation, rats were anesthetized with $2.5 \%$ isoflurane and the brain was removed for 2,3,5-triphenyltetrazolium chloride (TTC) staining (four rats for each group). The brain tissues were sliced into $1.0 \mathrm{~mm}$-thick coronal sections, incubated in 2\% TTC solution (Sigma-Aldrich; Merck KGaA) for 15 min at $37^{\circ} \mathrm{C}$ and then fixed in $4 \%$ paraformaldehyde for $3 \mathrm{~min}$. The red area represented normal brain tissue and the white area represented infarct tissue. The infarction area was calculated in a blinded manner with the PhotoShop CS6 (13.0) analysis system $\left(\right.$ Adobe $^{\circledR}$ ). The results are expressed as the percentage of infarcted area/total brain tissue area in the coronal sections.

Neurological testing. Neurobehavioral function assessments were performed on the third day after MCAO/reperfusion according to a previous protocol by Longa et al (33). The standard of the assessment was as follows: 0, no neurological functional impairment; 1 , failure to extend the contralateral forelimb; 2 , circling to the contralateral side; 3 , contralateral toppling of walking due to brain injury; and 4, no spontaneous walking and exhibition of a depressed level of consciousness. 
The testing was performed in a blinded manner regarding the group identity and there were four rats in each group.

$B B B$ permeability. Evans Blue was injected to evaluate $\mathrm{BBB}$ permeability (four rats for each group). In brief, after 3 days of $\mathrm{MCAO} /$ reperfusion, the animals were injected with $2 \%$ Evans blue solution ( $4 \mathrm{ml} / \mathrm{kg}$ body weight) through the tail vein. The circulation time (2, 4 and $24 \mathrm{~h}$ ) of Evans blue solution was first screened and $2 \mathrm{~h}$ of circulation was used in the present study $(34,35)$. Subsequently, the rats were anesthetized with $3 \%$ isoflurane and treated with $150 \mathrm{ml}$ of PBS for transcardial perfusion. and the brain was removed to separate the ischemic hemisphere. The brain tissue was then homogenized in $2 \mathrm{ml}$ DMSO and incubated at $50^{\circ} \mathrm{C}$ for $2 \mathrm{~h}$, followed by centrifugation $(10,000 \mathrm{x} \mathrm{g})$ at $4 \mathrm{C}$ for $30 \mathrm{~min}$. The supernatant was collected and the absorbance was recorded at $620 \mathrm{~nm}$ using a microplate reader (1510; Thermo Fisher Scientific, Inc.).

Brain edema. Brain tissues were collected on the third day after MCAO/reperfusion and the olfactory bulb and the tissue at $2 \mathrm{~mm}$ in front of the frontal pole were discarded. The remaining brain tissue was cut into slices of $2 \mathrm{~mm}$ thickness for brain water content determination (four rats for each group).

The specific method was as follows: A piece of aluminum foil was weighed to determine its mass $\left(\mathrm{m}_{\mathrm{A}}\right)$, the brain tissue was placed on the aluminum foil to measure the total weight $\left(m_{B}\right)$ and the wet weight $(\mathrm{WW})$ was calculated as $\left(\mathrm{m}_{\mathrm{B}}-\mathrm{m}_{\mathrm{A}}\right)$. The brain tissue was then wrapped loosely with aluminum foil and placed in a constant-temperature oven at $110^{\circ} \mathrm{C}$ for $12 \mathrm{~h}$ (36). After the tested brain tissue was returned to room temperature, its weight $\left(\mathrm{m}_{\mathrm{C}}\right)$ was determined to calculate the dry weight (DW). The formula for calculating the water content of brain tissue was as follows: (WW-DW)/WW x100\%.

Histological analysis. After 3 days of MCAO/reperfusion, the rats were placed in the supine position after anesthesia with $3 \%$ isoflurane and perfused with $60 \mathrm{ml}$ of $4 \%$ paraformaldehyde for $5 \mathrm{~min}$ after perfusion $150 \mathrm{ml}$ of PBS (pH 7.4) for $10 \mathrm{~min}$ and then the brain was rapidly removed. The intact brain tissue was fixed in $4 \%$ paraformaldehyde at room temperature for $48 \mathrm{~h}$, embedded in paraffin and cut into $5-\mu \mathrm{m}$ coronal sections. The sections were stained with $\mathrm{H} \& \mathrm{E}$ (three rats for each group). The histological features of the cerebral cortex and the striatum were observed under a light microscope (Olympus Corporation).

Immunofluorescence staining. Paraffin brain sections were prepared for immunofluorescence staining. The immunostaining procedure was performed as previously described (37). Briefly, deparaffinize and rehydrate: incubate sections in 3 changes of xylene, 10 min each. Dehydrate in 2 changes of pure ethanol for $5 \mathrm{~min}$, followed by dehydrate in gradient ethanol of 85 and $75 \%$ ethanol, respectively, 5 min each. Wash in distilled water. Antigen retrieval: immerse the slides in EDTA antigen retrieval buffer (Wuhan Servicebio Technology Co., Ltd.) and maintain at a boiling water for 35 min. Let air cooling. Wash three times with PBS ( $\mathrm{pH} 7.4)$ in a Rocker device, 5 min each. and blocked with $10 \%$ goat serum (Beyotime Biotechnology Co., Ltd.) at room temperature for $15 \mathrm{~min}$. Sections were first incubated with antibodies to CD31 (1:150 dilution; cat. no. GB12063; Wuhan Servicebio Technology Co., Ltd.) and $\alpha$-smooth muscle actin (SMA; 1:150 dilution; cat. no. GB111364; Wuhan Servicebio Technology Co., Ltd.) as indicators of vascular density (three rats for each group), VEGF (1:150 dilution; sc-7269; Santa) as an indicator of angiogenesis and neuronal nuclear protein (NeuN; 1:150 dilution; ab177417; Abcam) to visualize mature neurons, overnight at $4^{\circ} \mathrm{C}$. Subsequently, the sections were incubated with a suitable secondary antibody (anti-mouse IgG Alexa Flour ${ }^{\circledR} 488$ Conjugate; cat. no. 4408; CST; 1:200 dilution and $\mathrm{Cy}^{\mathrm{TM}} 3$-conjugated Affinipure Donkey anti-rabbit IgG; 152679; Jackson Immuno Research; 1:350 dilution). Cell nuclei were stained with DAPI. The paraffin sections were imaged with a Nikon fluorescence microscope (Olympus Corporation) and images were quantified with ImageJ software1.50i (NIH). All evaluations were performed by an investigator blinded to the experiment (five rats for each group).

TUNEL staining. TUNEL staining of paraffin sections of brain tissues was used to detect apoptotic cell death based on DNA fragmentation. TUNEL assays were performed according to the manufacturer's protocol (Roche Diagnostics). Slides were then counterstained with DAPI. The paraffin sections were imaged using a Nikon fluorescence microscope (Olympus Corporation) and images were quantitatively evaluated with ImageJ software1.50i [National Institutes of Health (NIH)]. Counting was performed in a blinded manner and there were five rats for each group.

Immunohistochemical staining. Paraffinized brain sections were dewaxed and dehydrated in xylene and ethanol solution, followed by antigen retrieval and blocking with $10 \%$ goat serum (Beyotime Biotechnology Co., Ltd.) at room temperature for $15 \mathrm{~min}$. All sections were then incubated with anti-VEGFR2 antibody (1:800 dilution; cat. no. 9698S; Cell Signaling Technology, Inc.) at $4^{\circ} \mathrm{C}$ overnight. Subsequently, the sections were washed in PBS three times and incubated with Horseradish peroxidase (HRP)-conjugated goat anti-rabbit IgG secondary antibodies (1:200 dilution; GB23303; Wuhan Servicebio Technology Co., Ltd.) for $10 \mathrm{~min}$ at room temperature. Next, the sections were visualized using a diaminobenzidine kit (Wuhan Servicebio Technology Co., Ltd.) and counterstained with hematoxylin. With a light microscope, an investigator blinded to the experimental groups randomly chose three separate tissue sections for each rat (four rats for each group). The staining was analyzed using ImageJ analysis software1.50i (NIH).

Reverse transcription-quantitative $(R T-q) P C R$. Brain tissues from the penumbra were separated and total RNA was extracted using TRIzol ${ }^{\circledR}$ reagent (CWBIO). Subsequently, the RNA was reverse transcribed to cDNA with a PrimeScript RT Reagent Kit (Takara Bio, Inc.) according to the manufacturer's instructions. cDNA was amplified with SYBR ${ }^{\circledR}$-Green Real-time PCR Master Mix (Takara Bio, Inc.) according to the manufacturer's instructions by RT-qPCR machine (QuantStudio 6 Flex, Thermo Fisher Scientific, Inc.). The following gene-specific primers: VEGF-A [forward (F), 5'-CGACAGAAGGGGAGC AGAAAG-3' and reverse (R), 5'-GCACTCCAGGGCTTCATC ATT-3'], Ang-1 (F, 5'-GTCACTGCACAAAAGGGACA-3' 
and R, 5'-GGCTTACAAGGATGGCGTTA-3'), VEGFR-2 (F, 5'-TAGCACGACAGAGACTGTGAGG-3' and R, 5'-TGAGG TGAGAGAGATGGGTAGG-3'), CD31 (F, 5'-TTTCGCTGC CAAGCTGGCGT-3' and R, 5'-CCACCTGCACGCTGCACT TGAT-3'), $\beta$-actin (F, 5'-GGGACCTGACTGACTACCTC-3' and R, 5'-TCATACTCCTGCTTGCTGAT-3') and basic fibroblast growth factor (bFGF) (F, 5'-GAGCGACCCACACGT CAAACTAC-3' and R, 5'-CAGCCGTCCATCTTCCTTCAT AGC-3'). The following thermocycling conditions were used for qPCR: Initial denaturation at $95^{\circ} \mathrm{C}$ for $30 \mathrm{sec}$, denaturation (40 cycles) at $95^{\circ} \mathrm{C}$ for $5 \mathrm{sec}$, annealing/extending (40 cycles) at $60^{\circ} \mathrm{C}$ for $30 \mathrm{sec}$. Melt curve at $95^{\circ} \mathrm{C}$ for $15 \mathrm{sec}$, at $60^{\circ} \mathrm{C}$ for $1 \mathrm{~min}$ and at $95^{\circ} \mathrm{C}$ for $15 \mathrm{sec}$. $\beta$-actin was used as a reference in the experiment. Relative mRNA expression was normalized to $\beta$-actin levels and analyzed with the $2^{-\Delta \Delta \mathrm{Cq}}$ method (38). Three rats were used for each group.

Statistical analysis. The neurological score data were presented as the median and interquartile range and data were analyzed with the Kruskal-Wallis test followed by Dunn's post-hoc test. All other data were expressed as the mean \pm standard deviation and differences between groups were compared by one-way ANOVA followed by Bonferroni's multiple-comparisons test. GraphPad 7.0 (GraphPad Software, Inc.) was used for all statistical analyses. ${ }^{*} \mathrm{P}<0.05,{ }^{* *} \mathrm{P}<0.01,{ }^{* * *} \mathrm{P}<0.001 ;{ }^{*} \mathrm{P}<0.05$, ${ }^{\# \#} \mathrm{P}<0.01,{ }^{\# \# \#} \mathrm{P}<0.001$; ${ }^{\& \&} \mathrm{P}<0.01$, ${ }^{\& \& \&} \mathrm{P}<0.001$ indicates a significant difference. ${ }^{*}$ Indicates compared with the vehicle group, \# indicates compared with the control group. \& indicates the STS group compared with the control group.

\section{Results}

STS decreases infarct size and neurological deficit scores. Cerebral ischemia injury was evaluated by neurological function scores and measurement of infarct size in rats. After 3 days of MCAO/reperfusion, the infarct area was assessed by TTC staining. The infarct area significantly increased in the vehicle group compared with the sham group. Compared with that in the vehicle group, the infarct area in the STS treatment group (30 $\mathrm{mg} / \mathrm{kg}$ ) and the edaravone group $(30 \mathrm{mg} / \mathrm{kg})$ was significantly reduced (Fig. 1A and B). The assessment of neurological deficits was determined. The rats in the sham-operated group had no neurological deficit. Conversely, the neurological deficit scores of the vehicle rats significantly increased. STS significantly ameliorated neurological function deficits at the dose of $30 \mathrm{mg} / \mathrm{kg}$ at 3 days after surgery, as did edaravone $(30 \mathrm{mg} / \mathrm{kg}$ ) (Fig. 1C). The above results indicated that the same dose of STS as that of edaravone $(30 \mathrm{mg} / \mathrm{kg})$ reduced cerebral infarction and improved neurological function. Thus, in subsequent experiments, STS and edaravone were used for further study at a dose of $30 \mathrm{mg} / \mathrm{kg}$.

STS preserves the integrity of the $B B B$ and reduces brain edema. To investigate whether STS has a protective effect on the BBB, the extent of BBB disruption was detected by leakage of Evans blue in the ipsilateral hemispheres after cerebral ischemia. After 3 days of $\mathrm{MCAO} /$ reperfusion, in the vehicle group, the BBB integrity was significantly decreased compared with the sham group. The BBB integrity in the STS $(30 \mathrm{mg} / \mathrm{kg})$ and edaravone $(30 \mathrm{mg} / \mathrm{kg}$ ) groups was significantly improved compared with that in the vehicle group (Fig. 1D and E). The therapeutic effect of STS on the MCAO/reperfusion model was also determined by the content of brain edema. The cerebral edema content of the vehicle group was significantly increased after injury compared with that in the sham group, while that in the STS $(30 \mathrm{mg} / \mathrm{kg})$ and edaravone $(30 \mathrm{mg} / \mathrm{kg})$ groups was significantly reduced compared with that in the vehicle group (Fig. 1F). These results indicated that STS attenuated pathological changes caused by cerebral ischemia.

Histopathological changes associated with STS treatment. To further verify the protective effects of STS on the MCAO/reperfusion model, morphological changes were observed by H\&E staining after 3 days of MCAO/reperfusion. The brain tissue was observed under a light microscope (Fig. 2). In the sham group, the structure of the brain tissue was clear and intact with no obvious pathological changes. The neurons in the cortex and striatum were clear and arranged in order. No cell structure damage was observed and no cytoplasmic vacuoles were detected. By contrast, the brain pathological structure was significantly changed in the vehicle group. The specific histopathological observations were as follows: The structure of the brain tissue was loose and numerous vacuoles in the cortex and striatum were present. Compared with that in the sham group, the cell morphology was irregular and the cell number was markedly decreased. In the STS $(30 \mathrm{mg} / \mathrm{kg})$ and edaravone $(30 \mathrm{mg} / \mathrm{kg})$ groups, the pathological changes in the cortex and striatum were significantly alleviated. The loosening of the tissue structure, shrinkage and cavitation of cells were obviously reversed in the cortex and striatum and the number of remaining cells was markedly increased compared with the vehicle group. Thus, STS had an effect to improve the pathology of cerebral ischemia/reperfusion injury similar to that of edaravone.

STS inhibits apoptotic cell death. To investigate the neuroprotective effects of STS against cerebral ischemia/reperfusion injury through inhibiting apoptotic cell death, NeuN protein, representing neurons in brain tissue, was labeled with fluorescent antibodies (Fig. 3A) and TUNEL staining was performed to detect apoptotic cell death in the penumbra area (Fig. 3B). As presented in Fig. 3A and C, numerous neurons were lost in the vehicle-treated brain sections compared with the sham group, while the survival rate of the cells in the STS $(30 \mathrm{mg} / \mathrm{kg}$ ) and edaravone $(30 \mathrm{mg} / \mathrm{kg})$ groups was significantly higher than that in the vehicle group. As presented in Fig. 3B and D, there was significant apoptosis in the vehicle compared with the sham group. The number of apoptotic cells in the STS $(30 \mathrm{mg} / \mathrm{kg}$ ) and edaravone $(30 \mathrm{mg} / \mathrm{kg}$ ) groups was significantly reduced compared with that in the vehicle group.

STS enhances vascular density in the penumbra. Angiogenesis has an important role in ischemic stroke-induced brain injury repair and long-term functional recovery $(39,40)$. Thus, in the present study, to evaluate whether STS promotes vascular density in the penumbra after 3 days of ischemia/reperfusion, the expression of the endothelial cell marker CD31 and vascular smooth muscle cell marker $\alpha$-SMA was examined via immunofluorescence (Fig. 4). The vascular density was significantly reduced in the vehicle group compared with that in the 
A

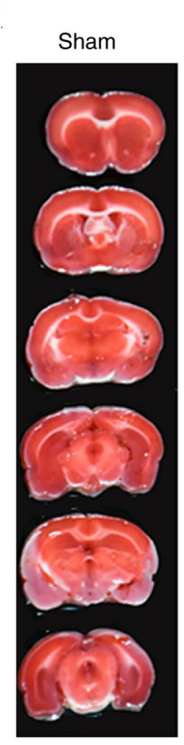

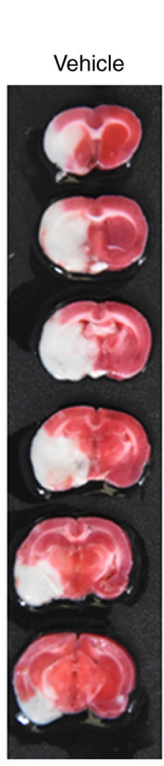

B

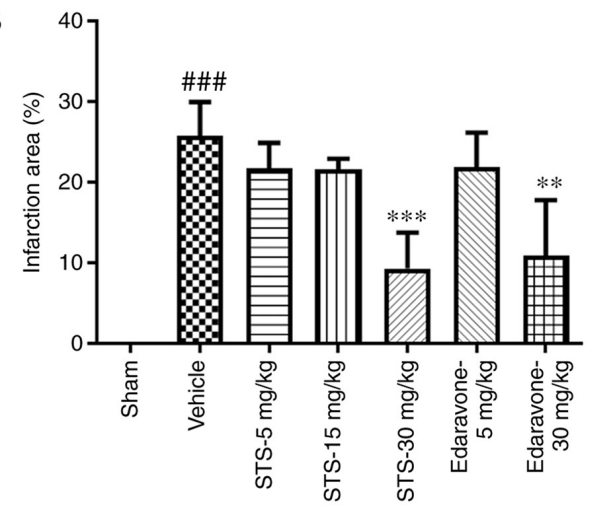

D

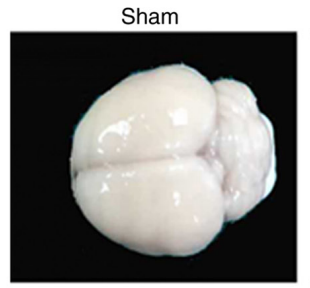

E

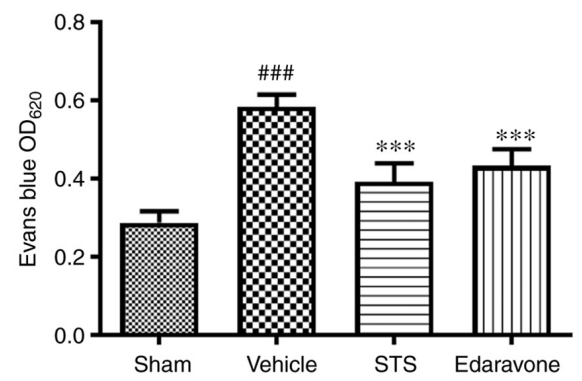

STS

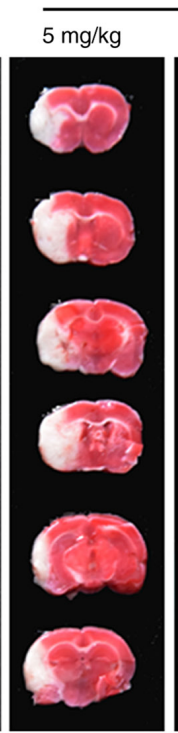

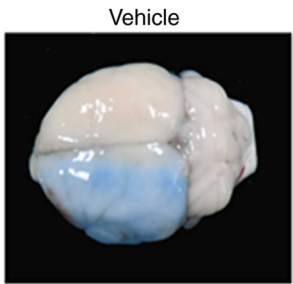
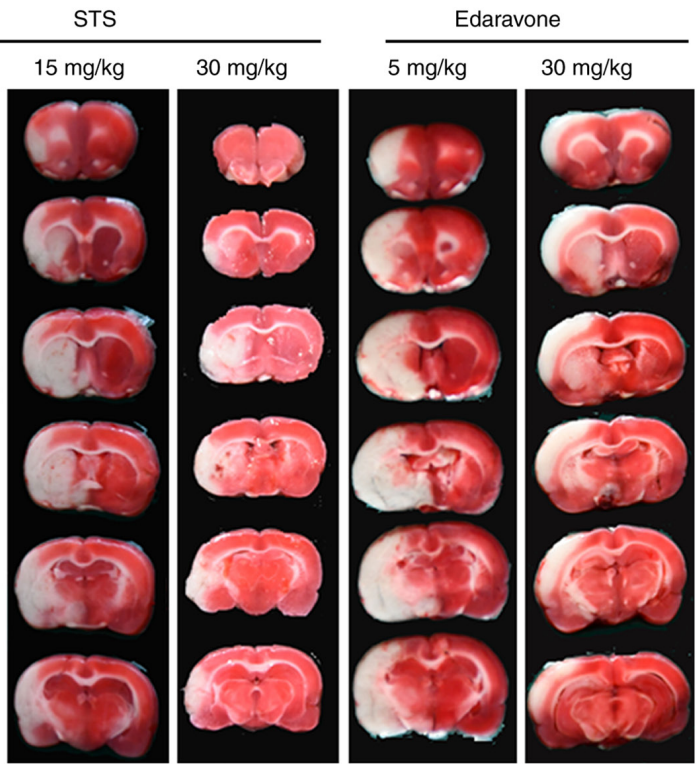

C
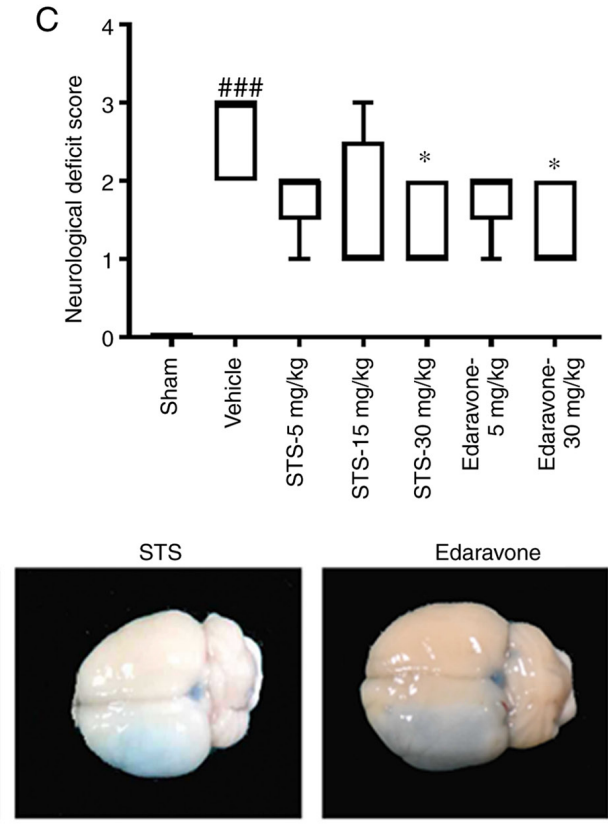

$\mathrm{F}$

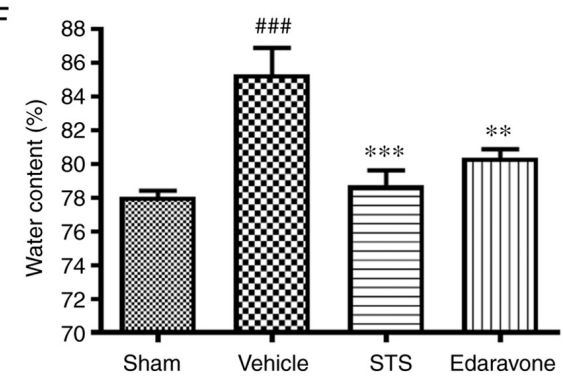

Figure 1. STS decreases the infarction area and neurological deficit scores, ameliorates the integrity of the blood-brain barrier and reduces brain edema 3 days after ischemia/reperfusion injury. (A) Representative images of 2,3,5-triphenyltetrazolium chloride staining of brain sections. (B) Quantified infarction area in the brain (\%). (C) Neurological deficit score in the different groups. (D) Representative images of brains following Evans blue injection in the Sham, Vehicle, STS-30 mg/kg and Edaravone- $30 \mathrm{mg} / \mathrm{kg}$ groups. (E) Absorbance values of Evans blue leakage $\left(\mathrm{OD}_{620}\right)$. (F) Brain water content in the different groups $(\%)$. Values are expressed as the mean \pm standard deviation ( $\mathrm{n}=4$ per group). ${ }^{* * *} \mathrm{P}<0.001,{ }^{* *} \mathrm{P}<0.01$ and ${ }^{*} \mathrm{P}<0.05$ compared with the vehicle group; and ${ }^{\# \# \#} \mathrm{P}<0.001$ compared with the sham group according to one-way ANOVA followed by Bonferroni's multiple-comparisons test. OD 620 , optical density at $620 \mathrm{~nm}$; STS, sodium tanshinone IIA sulfonate.

sham operation group, while in the STS $(30 \mathrm{mg} / \mathrm{kg})$ group, the vascular density was significantly increased compared with that in the vehicle group. However, edaravone treatment
$(30 \mathrm{mg} / \mathrm{kg}$ ) resulted in no significant change in vascular density. The above results indicated that STS was able to promote angiogenesis in the penumbra after cerebral ischemia. 

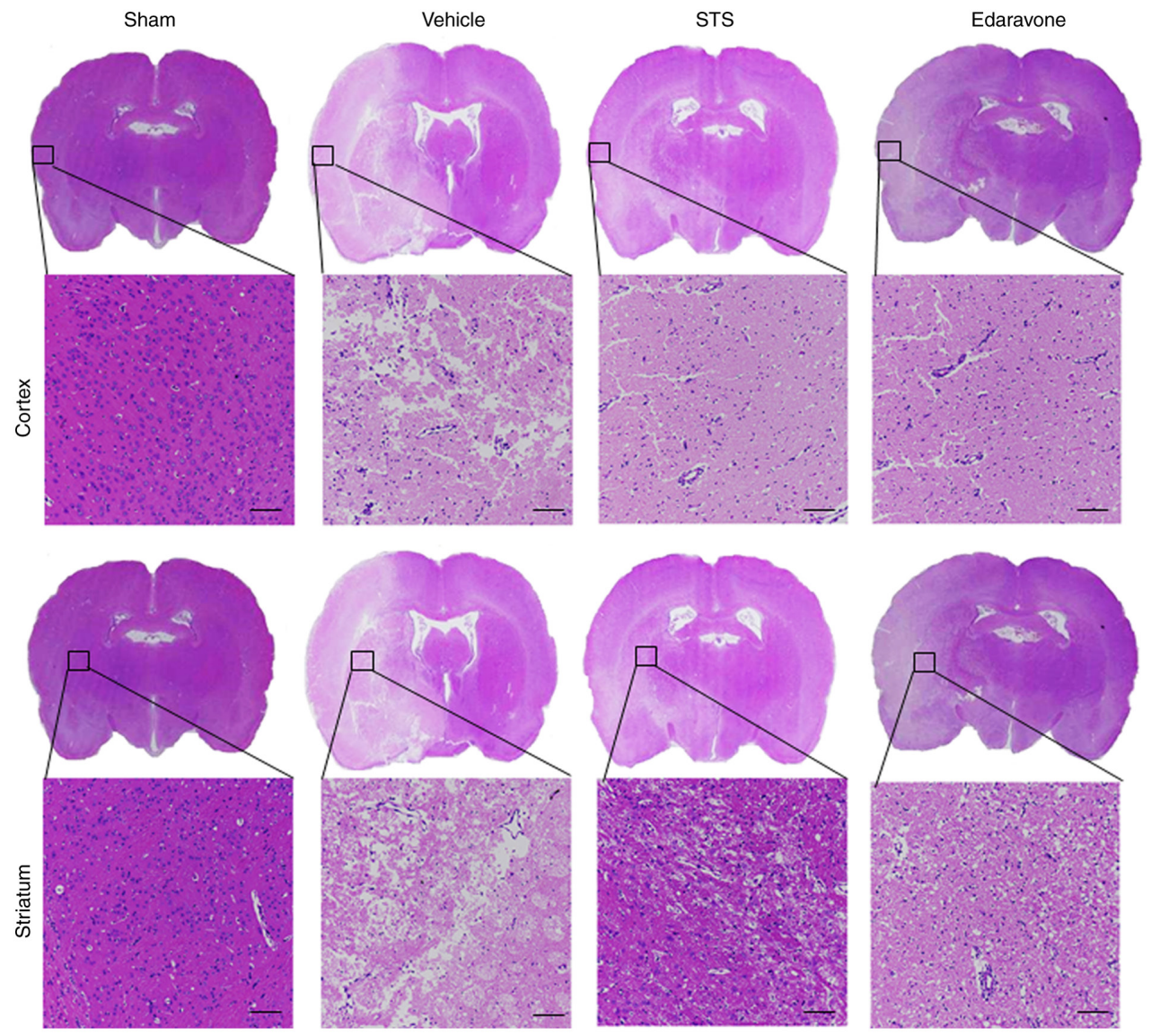

Figure 2. Effect of STS on histopathology. H\&E-stained cerebral cortex and striatum of brains after 3 days of middle cerebral artery occlusion/reperfusion. The images were acquired with a light microscope (scale bar, $100 \mu \mathrm{m}$ ). Images are representative of 3 animals per group. STS, sodium tanshinone IIA sulfonate.

STS increases the protein expression of VEGF and VEGFR2. VEGF/VEGFR2 signaling has the greatest effect to promote neurovascular regeneration after ischemic stroke (23). In the ischemia/reperfusion model of the present study, as presented in Fig. 5, the amount of VEGF protein in the vehicle group detected by immunofluorescence was significantly reduced compared with that in the sham group, while the expression of VEGF protein in the STS $(30 \mathrm{mg} / \mathrm{kg})$ group was significantly increased compared with that in the vehicle group after 3 days of ischemia/reperfusion (Fig. 5A and C). The same trend and effect of STS $(30 \mathrm{mg} / \mathrm{kg})$ on VEGFR2 protein levels were obtained using immunohistochemistry (Fig. 5B and D). However, no obvious changes in VEGF/VEGFR2 protein were observed after edaravone $(30 \mathrm{mg} / \mathrm{kg})$ treatment (Fig. 5).

STS promotes $m R N A$ expression of angiogenesis-related factors. To determine the effect of STS on regulatory factors of angiogenesis, the relative mRNA levels of the factors VEGF-A, Ang-1, VEGFR-2, CD31 and bFGF in brain tissue were determined using RT-qPCR. In the vehicle group, the mRNA expression of VEGF-A and CD31 was significantly reduced, the mRNA expression of VEGFR2, Ang-1 and bFGF was decreased, but not significantly compared with that in the sham group. Treatment with STS $(30 \mathrm{mg} / \mathrm{kg}$ ) significantly increased the mRNA expression of VEGF-A (Fig. 6A), VEGFR-2 (Fig. 6B), Ang-1 (Fig. 6C), CD31 (Fig. 6D) and bFGF (Fig. 6E) compared with that in the vehicle group. There was no significant difference between the edaravone group and vehicle group except for Ang-1 mRNA.

\section{Discussion}

Danshen separated from the dried root of Salvia miltiorrhiza, a traditional Chinese medicinal herb, is widely used for the prevention and treatment of various cardiovascular diseases in the clinic, including angina pectoris, hyperlipidemia and acute ischemic stroke $(41,42)$. Tanshinone IIA is an important monomer extracted from Danshen. To improve the poor water solubility of tanshinone IIA, STS was obtained by sulfonation to change the structure and increase the bioavailability. The present study focused on the protective effects of STS on brain damage induced by acute cerebral ischemia/reperfusion in rats and demonstrated that STS relieved cerebral injury after ischemia/reperfusion by promoting angiogenesis.

A clinical study revealed that STS improved neurologic functional outcomes for patients with acute ischemic stroke by reducing BBB leakage and damage (12). Injury to the BBB allows blood-borne cells, chemicals and fluids to flow into the brain, which may lead to complications, such as inflammatory responses and cerebral edema (43). In terms of clinical symptoms, BBB destruction has been indicated to be closely related to cerebral edema (44). In the present model of cerebral ischemia/reperfusion, it was indicated that STS was effective in reducing brain damage in rats with cerebral ischemia/reperfusion, including attenuation of cerebral infarction, protection of the integrity of the BBB and reduced brain edema. More importantly, STS also decreased the neurological deficit scores, reversed histopathological changes and reduced apoptotic cell 
A
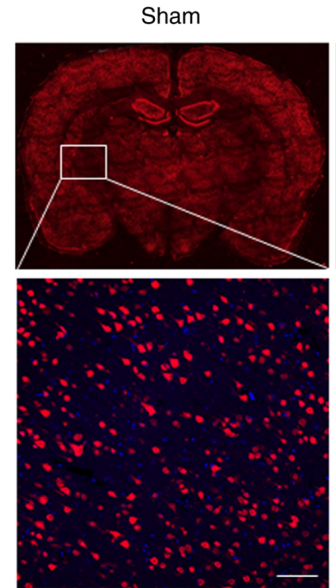

$\mathrm{B}$
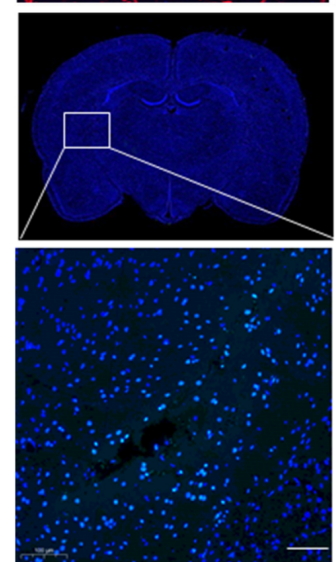

C

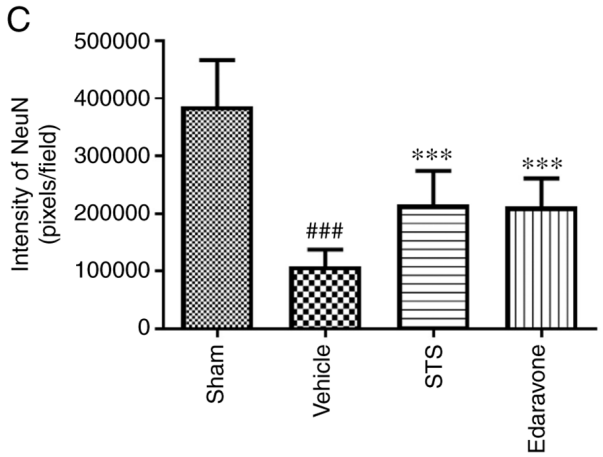

STS
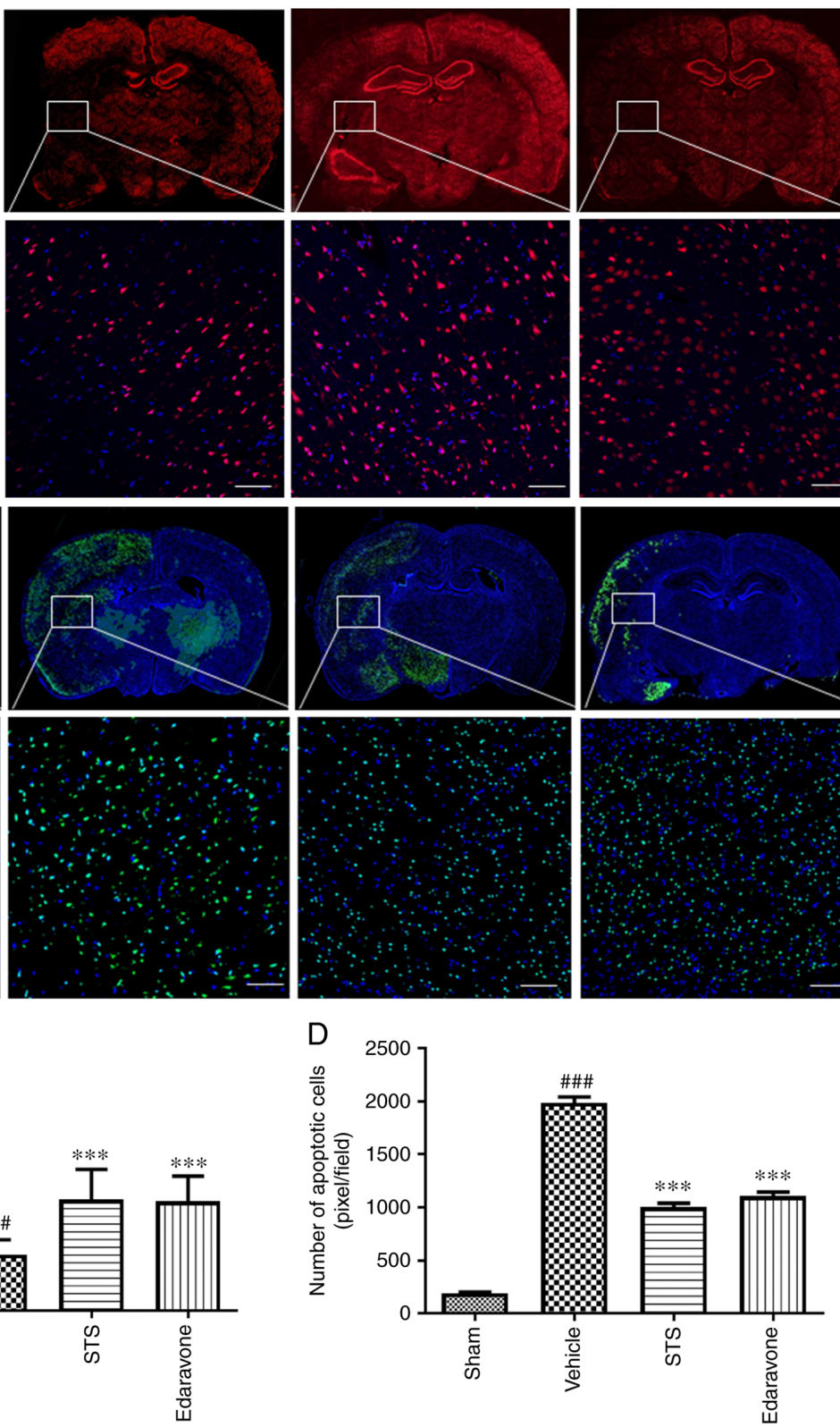

Figure 3. STS inhibits apoptotic cell death. (A) Immunofluorescence staining for NeuN (red, neurons). (B) Representative TUNEL-stained apoptotic cells (green) in the ischemic brain after 3 days of middle cerebral artery occlusion/reperfusion (scale bar, $100 \mu \mathrm{m}$; nuclei are stained in blue). (C) Rate of neuronal survival. (D) Quantified number of apoptotic cells. Values are expressed as the mean \pm standard deviation ( $=5$ per group). ${ }^{* * *} \mathrm{P}<0.001$ compared with the vehicle group; and ${ }^{\# \# \# ~} \mathrm{P}<0.001$ compared with the sham group according to one-way ANOVA followed by Bonferroni's multiple-comparisons test. STS, sodium tanshinone IIA sulfonate; NeuN, neuronal nuclear protein.

death. The magnitude of these protective effects of STS on cerebral ischemia/reperfusion injury in rats was similar to that of edaravone, a commonly used neuroprotective agent in the clinic. In the present study, 5,15 and $30 \mathrm{mg} / \mathrm{kg}$ doses of STS were used for some preliminary screening, and $30 \mathrm{mg} / \mathrm{kg}$ of STS was the most effective therapeutic dose. However, the best dose for treatment remains to be determined.

To further elucidate the protective mechanism of STS on cerebral ischemic/reperfusion injury in rats, the angiogenic effect of STS was further studied. Angiogenesis has an important role in the treatment of ischemic stroke (45). Pharmacological targeting of microcirculatory dysregulations has been indicated to be improved by angiogenesis (46) and STS has a protective effect on microcirculatory disturbance (47).
After a stroke, disruption of the BBB occurs acutely whereas regeneration of cerebral microvessels develops relatively late in ischemic brain (40), the body's own recovery is relatively slow, among which the acceleration of angiogenesis may be expected to enhance the prognosis (39), and STS accelerates neovascularization of the ischemic zone. In the present study, it was first verified that STS was able to increase the vascular density in the ischemic brain area. The effect of STS on the VEGF/VEGFR2 signaling pathway, which has a major role in angiogenesis, was also explored. VEGF is a growth factor that stimulates the proliferation of vascular endothelial cells and has vital roles in neovascular remodeling in ischemic stroke (43). In addition, VEGF possesses neurotrophic and neuroprotective activity and the direct neurotrophic effect of 

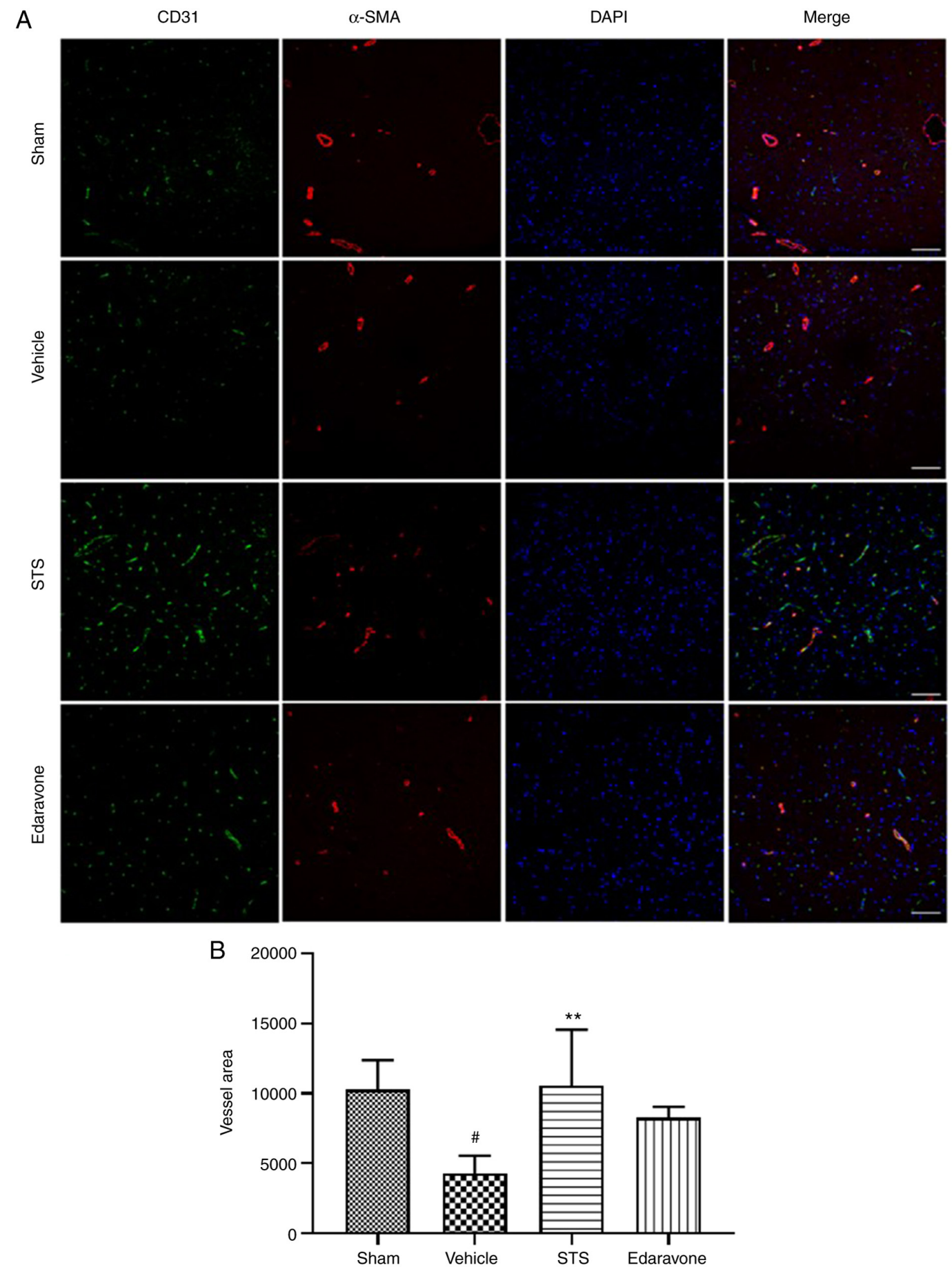

Figure 4. STS enhances the vascular density in the penumbra after 3 days of ischemia/reperfusion. (A) Representative images of brain tissues with microvessels displayed by immunostaining for CD31 and $\alpha$-SMA after 3 days of ischemia/reperfusion (scale bar, $100 \mu \mathrm{m}$ ). (B) Quantification of the formation of microvessels via quantification of the fluorescence intensity of CD31 in the ischemic boundary area. Values are expressed as the mean \pm standard deviation $(n=3$ per group). ${ }^{* *} \mathrm{P}<0.01$ compared with the vehicle group; and ${ }^{\#} \mathrm{P}<0.05$ compared with the sham group according to one-way ANOVA followed by Bonferroni's multiple-comparisons test. STS, sodium tanshinone IIA sulfonate; SMA, smooth muscle actin.

VEGF was able to confer neuroprotective activity independent of angiogenesis (48). However, whether STS promotes VEGF in cerebral ischemia has not been reported in the literature, to the best of our knowledge. The present study confirmed that STS promoted the protein expression of VEGF and VEGFR2 in ischemic brain tissue of rats, which may indicate that STS regulates angiogenesis by activating the VEGF/VEGFR2 signaling pathway. The protein expression of VEGF will be further detected with ELISAs in the serum and supernatant of brain tissue homogenate in future studies. In addition, the cell types expressing VEGF after STS treatment have remained elusive. Certain studies have raised that macrophages secrete various angiogenic growth factors (including VEGF) and neurotrophic factors to promote angiogenesis, preserve the cortical blood supply and improve neurological function in the acute phase of cerebral ischemia/reperfusion $(49,50)$. Next, the relationship between VEGF and macrophages will be further investigated. In the present study, the mRNA 

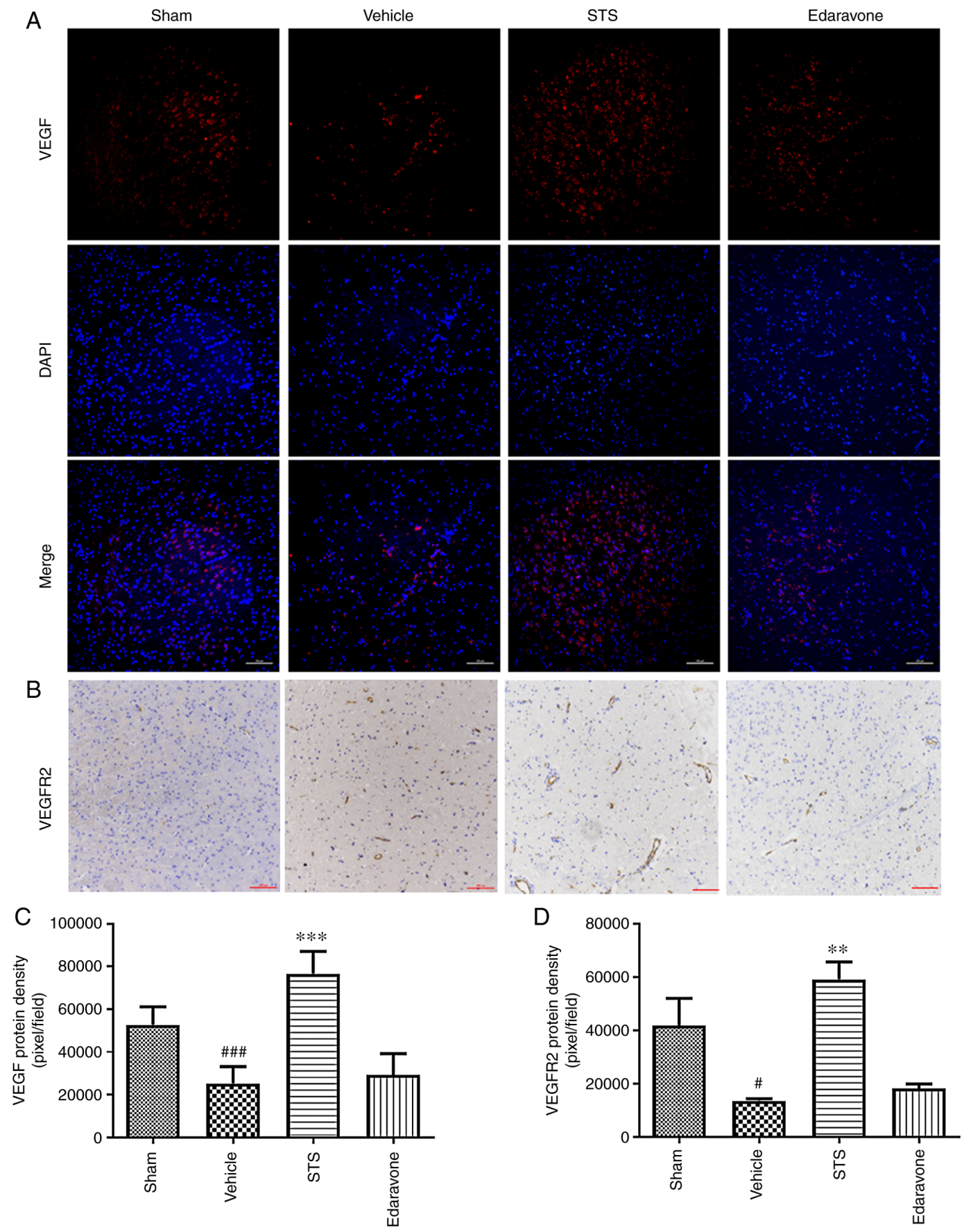

Figure 5. STS promotes the protein expression of VEGF and VEGFR2 in brain tissues after ischemia/reperfusion. (A) Representative immunofluorescence images of VEGF staining. (B) Representative immunohistochemical images of VEGFR2 staining (red: VEGF, brown: VEGFR2, scale bar, $100 \mu \mathrm{m}$ ). (C) Quantitative analysis providing the integrated intensity of VEGF staining. (D) Quantitative analysis of the integrated intensity of VEGFR2 staining. Values are expressed as the mean \pm standard deviation ( $\mathrm{n}=4$ per group). ${ }^{* * * *} \mathrm{P}<0.001,{ }^{* * *} \mathrm{P}<0.01$ compared with the vehicle group; and ${ }^{\# \# \# "} \mathrm{P}<0.001,{ }^{*} \mathrm{P}<0.05$ compared with the sham group according to one-way ANOVA followed by Bonferroni's multiple-comparisons test. STS, sodium tanshinone IIA sulfonate; VEGFR2, vascular endothelial growth factor receptor 2 .

expression levels of angiogenesis-related factors in the rat brain after cerebral ischemia were examined. The results indicated that the mRNA expression levels of VEGF-A, Ang-1, VEGFR-2, CD31 and bFGF in the rat brain after cerebral ischemia were reduced compared with the Sham group. However, STS could reverse this phenomenon and promote the expression of these angiogenesis-related factors compared with the vehicle group. Edaravone had no significant effect on any of these angiogenesis-related factors/processes apart from increasing Ang-1 expression. Therefore, STS was proven to be particularly effective in promoting angiogenesis following ischemic stroke.

In conclusion, the present study demonstrated that STS promoted angiogenesis by regulating the protein expression of VEGF and VEGFR2, and regulating the mRNA levels of angiogenesis-related factors, which may contribute to the angiogenesis-promoting effect of STS after cerebral ischemia, leading to reduction of the cerebral infarction area, relief of brain edema and improvement of BBB integrity, thereby promoting the recovery of neurobehavior after experimental stroke. 
A

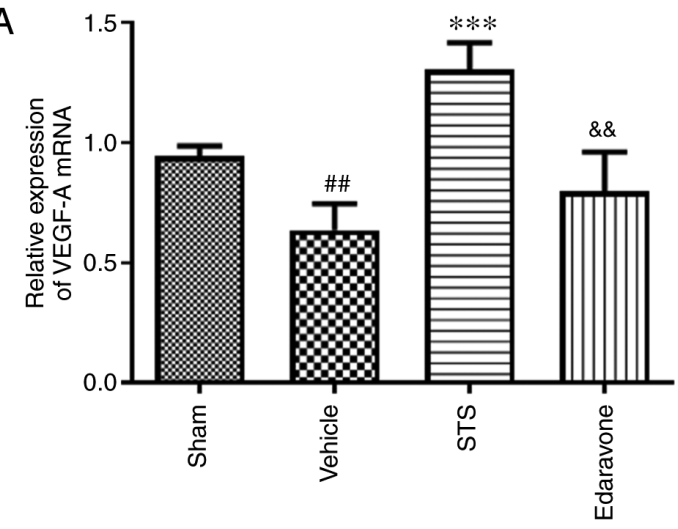

C

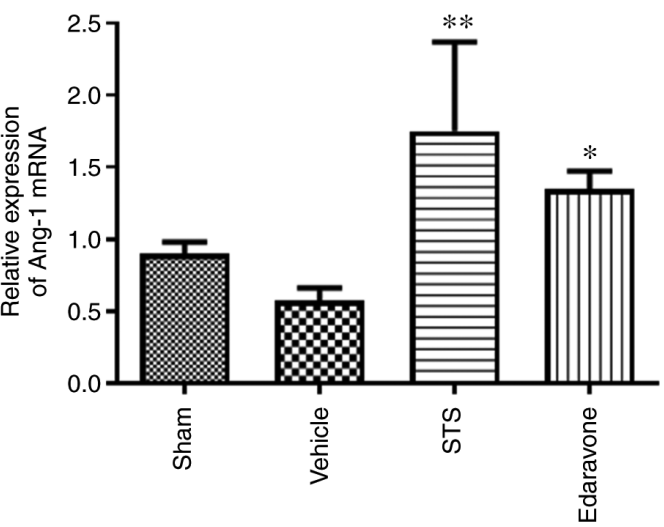

B

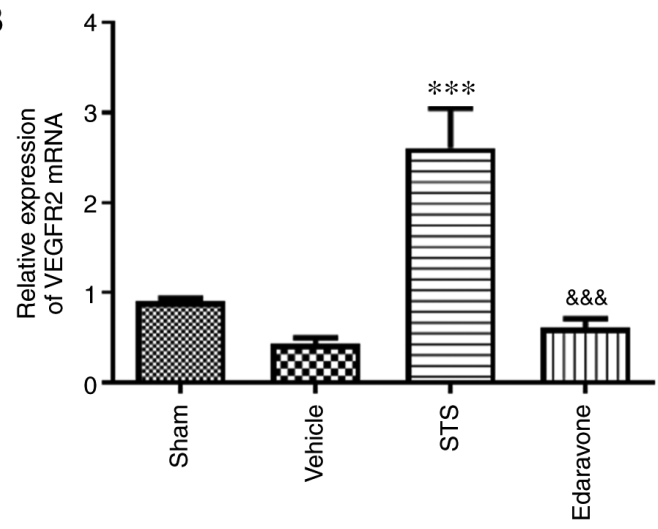

D

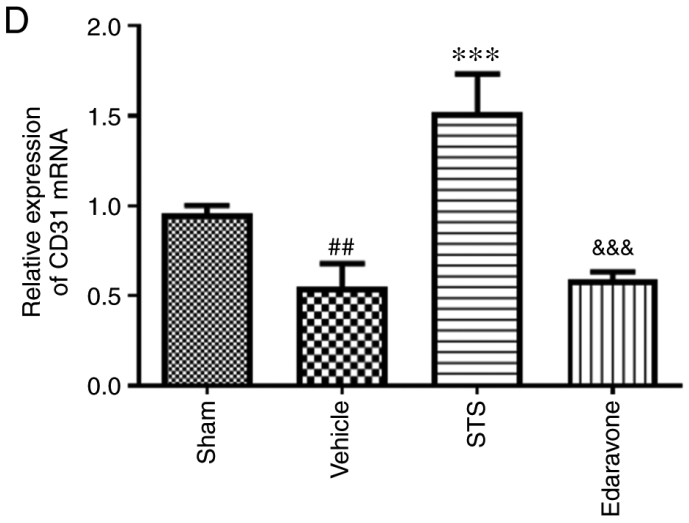

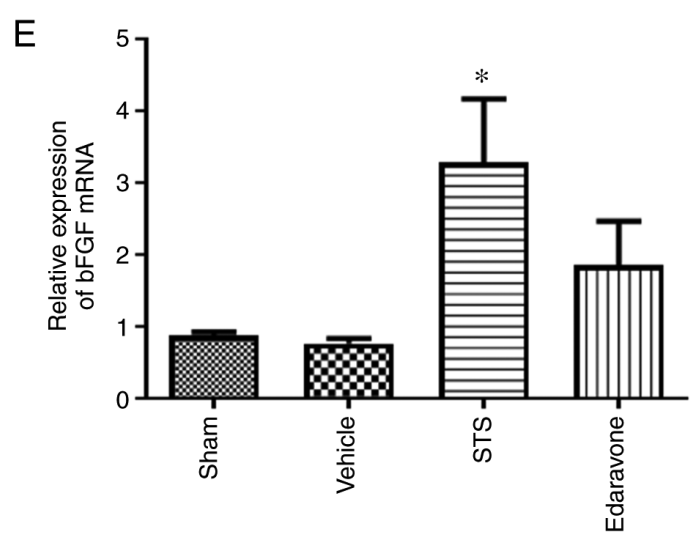

Figure 6. STS promotes the mRNA expression of angiogenesis-related factors in brain tissue after 3 days of ischemia/reperfusion. (A) Expression levels of VEGF-A mRNA. (B) Expression levels of VEGFR2 mRNA. (C) Expression levels of Ang-1 mRNA. (D) Expression levels of CD31 mRNA. (E) Expression levels of bFGF mRNA. Values are expressed as the mean \pm standard deviation $\left(\mathrm{n}=3\right.$ per group). ${ }^{* * * *} \mathrm{P}<0.001,{ }^{* *} \mathrm{P}<0.01$ and ${ }^{*} \mathrm{P}<0.05$ compared with the vehicle group; ${ }^{\# \#} \mathrm{P}<0.01$ compared with the sham group; and ${ }^{\& \& \&} \mathrm{P}<0.001$, \&\& $\mathrm{P}<0.01$ STS group compared with the Edaravone group, according to one-way ANOVA followed by Bonferroni's multiple-comparisons test. STS, sodium tanshinone IIA sulfonate; SMA, smooth muscle actin; VEGFR2, vascular endothelial growth factor receptor 2; bFGF, basic fibroblast growth factor; Ang-1, angiopoietin-1.

\section{Acknowledgements}

Not applicable.

\section{Funding}

The present study was supported by grants from the National Natural Science Foundation of China (grant nos. 81573579 and 82003800), the New Interdisciplinary Subject Funding Program for Shanghai Traditional Chinese Medicine (grant no. E2-F18003) and the Science and Technology Commission of Shanghai Municipality (grant nos. 18401933500 and 20ZR1473200).

\section{Availability of data and materials}

The datasets used and/or analyzed during the current study are available from the corresponding author upon reasonable request.

\section{Authors' contributions}

JZ and YZ designed the study. JX, PZ and YC performed the experiments. JX and YC analyzed the data. JX and YZ drafted the manuscript and $\mathrm{PZ}$ and JZ revised the manuscript. YX and PL helped with the data analysis. YZ and JX confirmed the authenticity of all the raw data. All authors have read and approved the final manuscript. 


\section{Ethics approval and consent to participate}

All animal experiments were approved by the Ethics Committee of the animal experiment center of Shanghai University of Traditional Chinese Medicine (Shanghai, China; approval no. PZSHUTCM19010411).

\section{Patient consent for publication}

Not applicable.

\section{Competing interests}

The authors declare that they have no competing interests.

\section{References}

1. Benjamin EJ, Blaha MJ, Chiuve SE, Cushman M, Das SR, Deo R, De Ferranti SD, Floyd JS, Fornage M, Gillespie C, et al: Heart disease and stroke statistics-2017 update: A report from the American heart association. Circulation 135: e146-e603, 2017.

2. Benjamin EJ, Virani SS, Callaway CW, Chamberlain AM, Chang AR, Cheng S, Chiuve SE, Cushman M, Delling FN, Deo R, et al: Heart disease and stroke statistics-2018 update: A report from the American heart association. Circulation 137: e67-e492, 2018.

3. Winstein CJ, Stein J, Arena R, Bates BE, Cherney LR, Cramer SC Deruyter F, Eng JJ, Fisher BE, Harvey RL, et al: Guidelines for adult stroke rehabilitation and recovery: A guideline for healthcare professionals from the American heart association/American stroke association. Stroke 47: e98-e169, 2016

4. Shang Q, Xu H and Huang L: Tanshinone IIA: A promising natural cardioprotective agent. Evid Based Complement Alternat Med 2012: 716459, 2012

5. Shang QH, Wang H, Li SM and Xu H: The effect of sodium tanshinone IIA sulfate and simvastatin on elevated serum levels of inflammatory markers in patients with coronary heart disease A study protocol for a randomized controlled trial. Evid Based Complement Alternat Med 2013: 756519, 2013

6. Tang J, Zhu C, Li ZH, Liu XY, Sun SK, Zhang T, Luo ZJ, Zhang H and $\mathrm{Li}$ WY: Inhibition of the spinal astrocytic JNK/MCP-1 pathway activation correlates with the analgesic effects of tanshinone IIA sulfonate in neuropathic pain. J Neuroinflamm 12: 57, 2015.

7. Zhang H, Long M, Wu Z, Han X and Yu Y: Sodium tanshinone IIA silate as an add-on therapy in patients with unstable angina pectoris. J Thorac Dis 6: 1794-1799, 2014.

8. Zhao YP, Wang F, Jiang W, Liu J, Liu BL, Qi L and Zhou W: A mitochondrion-targeting tanshinone IIA derivative attenuates myocardial hypoxia reoxygenation injury through a SDH-dependent antioxidant mechanism. J Drug Target 27 : 896-902, 2019

9. Hu Q, Wei B, Wei L, Hua K, Yu X, Li H and Ji H: Sodium tanshinone IIA sulfonate ameliorates ischemia-induced myocardial inflammation and lipid accumulation in beagle dogs through NLRP3 inflammasome. Int J Cardiol 196: 183-192, 2015.

10. Xu W, Yang J and Wu LM: Cardioprotective effects of tanshinone IIA on myocardial ischemia injury in rats. Pharmazie 64 332-336, 2009.

11. Morton JS, Andersson IJ, Cheung P, Baker PN and Davidge ST: The vascular effects of sodium tanshinone IIA sulphonate in rodent and human pregnancy. PLoS One 10: e0121897, 2015.

12. Ji B, Zhou F, Han L, Yang J, Fan H, Li S, Li J, Zhang X, Wang X and Chen X: Sodium tanshinone IIA sulfonate enhances effectiveness Rt-PA treatment in acute ischemic stroke patients associated with ameliorating blood-brain barrier damage. Transl Stroke Res 8: 334-340, 2017.

13. Zhou ZY, Huang B, Li S, Huang XH, Tang JY, Kwan YW, Hoi PM and Lee SMY: Sodium tanshinone IIA sulfonate promotes endothelial integrity via regulating VE-cadherin dynamics and RhoA/ROCK-mediated cellular contractility and prevents atorvastatin-induced intracerebral hemorrhage in zebrafish. Toxicol Appl Pharmacol 350: 32-42, 2018.
14. Li Z, Zhang S, Cao L, Li W, Ye YC, Shi ZX, Wang ZR, Sun LX, Wang JW, Jia LT and Wang W: Tanshinone IIA and Astragaloside IV promote the angiogenesis of mesenchymal stem cell-derived endothelial cell-like cells via upregulation of $\mathrm{Cx} 37, \mathrm{Cx} 40$ and Cx43. Exp Ther Med 16: 1847-1854, 2018.

15. Garcia JH, Wagner S, Liu KF and Hu XJ: Neurological deficit and extent of neuronal necrosis attributable to middle cerebral artery occlusion in rats. Statistical validation. Stroke 26: 627-635, 1995.

16. Lo EH: A new penumbra: Transitioning from injury into repair after stroke. Nat Med 14: 497-500, 2008.

17. Ma F, Morancho A, Montaner J and Rosell A: Endothelial progenitor cells and revascularization following stroke. Brain Res 1623: 150-159, 2015.

18. Jiang Y, Li L, Ma J, Zhang L, Niu F, Feng T and Li C: Auricular vagus nerve stimulation promotes functional recovery and enhances the post-ischemic angiogenic response in an ischemia/reperfusion rat model. Neurochem Int 97: 73-82, 2016.

19. Han L, Li J, Chen Y, Zhang M, Qian L, Chen Y, Wu Z, Xu Y and Li J: Human urinary kallidinogenase promotes angiogenesis and cerebral perfusion in experimental stroke. PLoS One 10: e0134543, 2015.

20. Hui Z, Sha DJ, Wang SL, Li CS, Qian J, Wang JQ, Zhao Y, Zhang JH, Cheng HY, Yang H, et al: Panaxatriol saponins promotes angiogenesis and enhances cerebral perfusion after ischemic stroke in rats. BMC Complement Altern Med 17: 70, 2017.

21. Petcu EB, Smith RA, Miroiu RI and Opris MM: Angiogenesis in old-aged subjects after ischemic stroke: A cautionary note for investigators. J Angiogenes Res 2: 26, 2010.

22. Arai K, Jin G, Navaratna D and Lo EH: Brain angiogenesis in developmental and pathological processes: Neurovascular injury and angiogenic recovery after stroke. FEBS J 276: 4644-4652, 2009.

23. Li W, Fraser JL, Yu SP, Zhu J, Jiang Y and Wei L: The role of VEGF/VEGFR2 signaling in peripheral stimulation-induced cerebral neurovascular regeneration after ischemic stroke in mice. Exp Brain Res 214: 503-513, 2011.

24. Lee DH, Lee J, Jeon J, Kim KJ, Yun JH, Jeong HS, Lee EH, Koh YJ and Cho CH: Oleanolic acids inhibit vascular endothelial growth factor receptor 2 signaling in endothelial cells: Implication for anti-angiogenic therapy. Mol Cells 41: 771-780, 2018.

25. Wise GE and Yao S: Expression of vascular endothelial growth factor in the dental follicle. Crit Rev Eukaryot Gene Expr 13: 173-180, 2003

26. Krum JM, Mani N and Rosenstein JM: Angiogenic and astroglial responses to vascular endothelial growth factor administration in adult rat brain. Neuroscience 110: 589-604, 2002.

27. Melincovici CS, Boșca AB, Şuşman S, Mărginean M, Mihu C, Istrate M, Moldovan IM, Roman AL and Mihu CM: Vascular endothelial growth factor (VEGF)-key factor in normal and pathological angiogenesis. Rom J Morphol Embryol 59: 455-467, 2018.

28. Wang Y, Jin K, Mao XO, Xie L, Banwait S, Marti HH and Greenberg DA: VEGF-overexpressing transgenic mice show enhanced post-ischemic neurogenesis and neuromigration. J Neurosci Res 85: 740-747, 2007.

29. Asahara T, Chen D, Takahashi T, Fujikawa K, Kearney M, Magner M, Yancopoulos GD and Isner JM: Tie2 receptor ligands, angiopoietin-1 and angiopoietin-2, modulate VEGF-induced postnatal neovascularization. Circ Res 83: 233-240, 1998.

30. Wang L, Xiong X, Zhang X, Ye Y, Jian Z, Gao W and Gu L: Sodium tanshinone IIA sulfonate protects against cerebral ischemia-reperfusion injury by inhibiting autophagy and inflammation. Neuroscience 441: 46-57, 2020.

31. Chen L, He W, Peng B, Yuan M, Wang N, Wang J, Lu W and Wang T: Sodium tanshinone IIA sulfonate improves post-ischemic angiogenesis in hyperglycemia. Biochem Biophys Res Commun 520: 580-585, 2019.

32. Zhou Z, Wei X, Xiang J, Gao J, Wang L, You J, Cai Y and Cai D: Protection of erythropoietin against ischemic neurovascular unit injuries through the effects of connexin43. Biochem Biophys Res Commun 458: 656-662, 2015.

33. Longa EZ, Weinstein P, Carlson S and Cummins R: Reversible middle cerebral artery occlusion without craniectomy in rats. Stroke 20: 84-91, 1989.

34. Wang J, Zhang D, Fu X, Yu L, Lu Z, Gao Y, Liu X, Man J, Li S, Li N, et al: Carbon monoxide-releasing molecule-3 protects against ischemic stroke by suppressing neuroinflammation and alleviating blood-brain barrier disruption. J Neuroinflammation 15: 188, 2018. 
35. Li D, Lang W, Zhou C, Wu C, Zhang F, Liu Q, Yang S and Hao J: Upregulation of microglial ZEB1 ameliorates brain damage after acute ischemic stroke. Cell Rep 22: 3574-3586, 2018.

36. Gilmer LK, Roberts KN and Scheff SW: Efficacy of progesterone following a moderate unilateral cortical contusion injury. J Neurotrauma 25: 593-602, 2008.

37. Luan P, Xu J, Ding X, Cui Q, Jiang L, Xu Y, Zhu Y, Li R, Lin G, Tian $\mathrm{P}$ and Zhang J: Neuroprotective effect of salvianolate on cerebral ischaemia-reperfusion injury in rats by inhibiting the caspase-3 signal pathway. Eur J Pharmacol 872: 172944, 2020.

38. Zhu Y, Yang L, Xu J, Yang X, Luan P, Cui Q, Zhang P, Wang F Li R, Ding X, et al: Discovery of the anti-angiogenesis effect of eltrombopag in breast cancer through targeting of $\mathrm{HuR}$ protein. Acta Pharm Sin B 10: 1414-1425, 2020.

39. Taguchi A, Soma T, TanakaH, Kanda T, Nishimura H, Yoshikawa H, Tsukamoto Y, Iso H, Fujimori Y, Stern DM, et al: Administration of $\mathrm{CD} 34^{+}$cells after stroke enhances neurogenesis via angiogenesis in a mouse model. J Clin Invest 114: 330-338, 2004.

40. Zhang ZG, Zhang L, Jiang Q, Zhang RL, Davies K, Powers C, Bruggen NV and Chopp M: VEGF enhances angiogenesis and promotes blood-brain barrier leakage in the ischemic brain. J Clin Invest 106: 829-838, 2000.

41. Zhou L, Zuo Z and Chow MS: Danshen: An overview of its chemistry, pharmacology, pharmacokinetics, and clinical use. J Clin Pharmacol 45: 1345-1359, 2005.

42. Chan P,LiuIM,Li YX, Yu WJ and Cheng JT: Antihypertension induced by tanshinone IIA isolated from the roots of Salvia miltiorrhiza. Evid Based Complement Alternat Med 2011: 392627, 2011.

43. Gong P, Zhang Z, Zou C, Tian Q, Chen X, Hong M, Liu X, Chen Q, Xu Z, Li M and Wang J: Hippo/YAP signaling pathway mitigates blood-brain barrier disruption after cerebral ischemia/reperfusion injury. Behav Brain Res 356: 8-17, 2019.

44. Giraud M, Cho TH, Nighoghossian N, Maucort-Boulch D, Deiana G, Østergaard L, Baron JC, Fiehler J, Pedraza S, Derex L and Berthezène Y: Early blood brain barrier changes in acute ischemic stroke: A sequential MRI study. J Neuroimaging 25: 959-963, 2015.
45. Navaratna D, Guo S, Arai K and Lo EH: Mechanisms and targets for angiogenic therapy after stroke. Cell Adh Migr 3: 216-223, 2009.

46. Ampofo E, Schmitt BM, Menger MD and Laschke MW: Targeting the microcirculation by indole-3-carbinol and its main derivate 3,3,'-diindolylmethane: Effects on angiogenesis, thrombosis and inflammation. Mini Rev Med Chem 18: 962-968, 2018.

47. Zhu W, Lv Q, Chen H, Wang Z and Zhong Q: Protective effect and mechanism of sodium tanshinone II A sulfonate on microcirculatory disturbance of small intestine in rats with sepsis. J Huazhong Univ Sci Technolog Med Sci 31: 441, 2011.

48. Sun Y, Jin K, Xie L, Childs J, Mao XO, Logvinova A and Greenberg DA: VEGF-induced neuroprotection, neurogenesis, and angiogenesis after focal cerebral ischemia. J Clin Invest 111: 1843-1851, 2003.

49. Liu J, Wang Y, Akamatsu Y, Lee CC, Stetler RA, Lawton MT and Yang GY: Vascular remodeling after ischemic stroke: Mechanisms and therapeutic potentials. Prog Neurobiol 115: 138-156, 2014.

50. Pedragosa J,Salas-Perdomo A, Gallizioli M, Cugota R, Miró-Mur F, Briansó F, Justicia C, Pérez-Asensio F, Marquez-Kisinousky L, Urra X, et al: CNS-border associated macrophages respond to acute ischemic stroke attracting granulocytes and promoting vascular leakage. Acta Neuropathol Commun 6: 76, 2018.

(c) (1) () This work is licensed under a Creative Commons cc) Attribution-NonCommercial-NoDerivatives 4.0 International (CC BY-NC-ND 4.0) License. 